\title{
Sensory neuropraxia of the median nerve in a perilunate injury: a review of a near miss
}

\author{
Chloe R. Wong ${ }^{1}$ (1) $\cdot$ Nathan Sacevich $^{1} \cdot$ Matthew C. McRae $^{1} \cdot$ James Heywood $^{1} \cdot$ Suneel Upadhye ${ }^{1}$
}

Received: 3 February 2021 / Accepted: 5 May 2021 / Published online: 16 May 2021

(c) The Author(s), under exclusive licence to Canadian Association of Emergency Physicians (CAEP)/ Association Canadienne de Médecine d'Urgence (ACMU) 2021

Keywords Wrist injuries · Median nerve $\cdot$ Missed diagnosis $\cdot$ Orthopedic surgeons $\cdot$ Plastic surgeons $\cdot$ Medical students

\section{Introduction}

Perilunate injuries result from high-energy trauma, including falls from height, motor vehicle accidents, or sporting activities [1]. They are rare injuries, with diagnoses missed in $25 \%$ of cases [2]. A high index of suspicion, thorough upper extremity evaluation, and wrist radiographs are crucial [2].

\section{Case presentation}

A 40-year-old right-hand dominant, healthy male presented to the emergency department (ED) with a tender left wrist following a forced extension injury while dirt biking. Wrist radiographs were reported as unremarkable by the radiologist and the patient was subsequently cleared by the ED physician.

The medical student was then sent to splint the patient for follow-up in clinic in 1 week. On examination, his wrist was swollen and demonstrated a volar hematoma. Active and passive wrist range of motion were significantly limited by pain. There was diminished sensation in the median nerve distribution of the hand, with a positive Tinel's sign at the carpal tunnel. Sensory examinations of the radial and ulnar nerve were normal. Motor examination of the median, radial, and ulnar nerve were normal.

With a high clinical suspicion of a perilunate injury, the medical student evaluated the index radiographs. A volar lunate dislocation was diagnosed after identifying a positive "spilled tea cup" sign on the lateral X-ray (Fig. 1,

Chloe R. Wong

chloe.wong@medportal.ca

1 McMaster University, 1280 Main Street West, Hamilton, ON L8S 4L8, Canada
Supplemental Figs. 1-3). Following review with the ED physician who had not seen the lateral X-ray, an orthopedic surgeon was consulted. Closed reduction was unsuccessful (Supplemental Figs. 4 and 5). The patient was admitted for emergency surgery, specifically: percutaneous pinning of the proximal and midcarpal rows using $1.6 \mathrm{~mm} \mathrm{k}$-wires, scapholunate and lunotriquetral ligament repairs using minisuture anchors, and median nerve decompression (Supplemental Figs. 6 and 7). Post-operatively, he was immobilized in a cast for 6 weeks. Although this patient's long-term outcome data are not yet available, progressive posttraumatic arthritis is expected [2]. Consent was obtained for this report.

\section{Discussion}

\section{Perilunate injuries}

The Mayfield classification of perilunar instability delineates stages I, II, and III as disruptions of the scapholunate, lunocapitate, and lunotriquetral ligamentous complexes, respectively [1]. In stage IV, the lunate ultimately dislocates from its fossa, rotating volarly into the carpal tunnel, and the capitate becomes aligned with the radius [1]. Acute median neuropathy is most common in this stage due to direct compression of the median nerve by the dislocated lunate [3]. Ligamentous injuries are known as lesser arc injuries, whereas greater arc injuries involve radial styloid, scaphoid, capitate, lunate, triquetrum, or hamate fractures [1].

\section{Diagnosis}

Patients may exhibit swelling, pain, and limited wrist range of motion [1]. The PA radiograph should be analyzed for: 


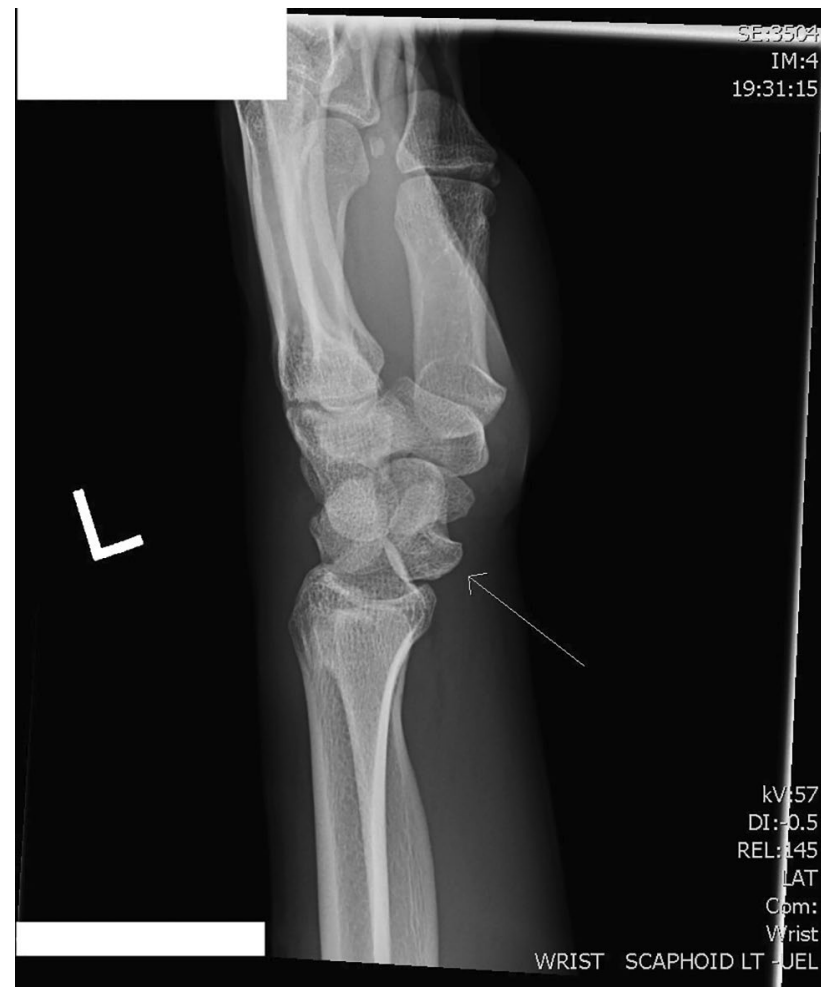

Fig. 1 Lateral radiograph of a lunate dislocation with a "spilled teacup" sign

gapping of carpal bones and discontinuity in Gilula's carpal arcs (Supplemental Fig. 8) [1]. The first arc is the proximal convexity of the triquetrum, lunate, and scaphoid [1]. The second arc is the concave distal surfaces of the aforementioned bones [1]. The third arc is the proximal hamate and capitate [1]. Lateral radiographs are essential to a radiographic diagnosis of a perilunate injury. In a true lateral view, the pisiform is positioned between the distal pole of the scaphoid and the capitate (Supplemental Fig. 9). The lateral radiograph should be analyzed for disrupted collinearity of the radius, lunate, and capitate, in particular, volar displacement of the lunate ("spilled tea cup" sign) [1]. When uncertain, X-rays of the injured wrist may be compared to the contralateral side, advanced imaging (i.e., CT scan) may be obtained, or surgery or radiology colleagues may be consulted to minimize diagnostic errors [4].

\section{Acute median neuropathy}

Symptoms of median nerve dysfunction occur due to compression by the dislocated lunate and increased pressure within the carpal tunnel due to blood and edema [1, 3]. However, only $23-45 \%$ of initial presentations of PLI have acute median neuropathy [3]. When present, an immediate closed reduction is imperative $[2,5]$. If symptoms fail to improve or worsen, an urgent operative reduction is needed to prevent permanent median nerve damage $[2,5]$. This may include severe atrophy of the thenar musculature and dense sensory loss, in which a carpal tunnel release will only inhibit progression rather than completely resolving median nerve dysfunction [5].

\section{Treatment}

An immediate closed reduction under conscious sedation is indicated to decompress the median nerve, improve swelling, release tension on the vascular supply to the displaced lunate, and limit articular cartilage damage [2,5]. The elbow is flexed to $90^{\circ}$ and the wrist is extended with traction and then flexed, with a palpable clunk on successful reduction [1]. Closed reduction and immobilization of perilunate injuries leads to a loss of reduction in up to $59 \%$ of cases, along with persistent carpal instability, pain, and weakness [1,2]. Thus, definitive surgical management is the gold standard for managing perilunate injuries [2].

\section{Missed diagnoses}

Factors associated with missed diagnoses include: lack of understanding of the complex carpal anatomy, injury severity, polytrauma, additional wrist fractures, lack of familiarity of the physician, and inadequate radiographs [4]. Particularly, lack of exposure has been identified as a significant factor in missed diagnoses. Emergency medicine training in orthopedic surgery/radiology subspecialties has been suggested to increase experience with rare injuries [4].

Complications of missed perilunate injuries include: median nerve injury, chronic carpal instability, avascular necrosis of the mal-reduced lunate, complex regional pain syndrome, unreliable return of function, hand/wrist weakness/stiffness, attritional tendon ruptures or dysfunctions, and posttraumatic arthrosis requiring a secondary procedure [1]. A 45-day delay in diagnosis is associated with significantly clinically worse outcomes [2]. Moreover, a 6-8-week delay in treatment results in volar ligament contracture and irreversible carpal bone ischemia, necessitating salvage procedures. This may include a proximal row carpectomy if the capitate head and lunate fossa are conserved, which improves pain, range of motion, and grip strength [2]. Severe pancarpal arthritis necessitates a complete wrist arthrodesis [2]. 


\section{Conclusion}

Perilunate injuries are rare, but devastating injuries when there is a delay in diagnosis. Prompt recognition by ED physicians facilitates optimal surgical management and satisfactory long-term clinical outcomes. The finding of acute sensory neuropraxia of the median nerve in the setting of high-energy wrist trauma should prompt re-evaluation of cleared radiographs to identify and manage perilunate injuries in a timely manner.

\section{Take away}

Presentation of traumatic wrist injuries in EDs necessitates comprehensive clinical and radiological exams to identify rare but functionally important diagnoses of perilunate injuries, which have poor long-term sequelae if missed.

Supplementary Information The online version contains supplementary material available at https://doi.org/10.1007/s43678-021-00144-5.

\section{Declarations}

Conflict of interest The authors declare that they have no conflict of interest.

\section{References}

1. Stanbury SJ, Elfar JC. Perilunate dislocation and perilunate fracture-dislocation. J Am Acad Orthop Surg. 2011;19(9):554-62.

2. Jones DB Jr, Kakar S. Perilunate dislocations and fracture dislocations. J Hand Surg. 2012;37(10):2168-73.

3. Wickramasinghe NR, Duckworth AD, Clement ND, Hageman MG, McQueen MM, Ring D. Acute median neuropathy and carpal tunnel release in perilunate injuries can we predict who gets a median neuropathy? J Hand Microsurg. 2015;7(2):237-40.

4. Çolak I, Bekler HI, Bulut G, Eceviz E, Gülabi D, Çeçen GS. Lack of experience is a significant factor in the missed diagnosis of perilunate fracture dislocation or isolated dislocation. Acta Orthop Traumatol Turc. 2018;52(1):32-6.

5. Wolfe SW, Hotchkiss RN, Pederson WC, Kozin SH, Cohen MS, editors. Green's Operative Hand Surgery. 7th ed: Elsevier Inc; 2016.

Publisher's Note Springer Nature remains neutral with regard to jurisdictional claims in published maps and institutional affiliations. 